\title{
Meridian-scanning photometer, coherent HF radar, and magnetometer observations of the cusp: a case study
}

\author{
S. E. Milan ${ }^{1}$, M. Lester ${ }^{1}$, S. W. H. Cowley ${ }^{1}$, J. Moen ${ }^{2}$, P. E. Sandholt ${ }^{3}$, C. J. Owen ${ }^{4}$ \\ ${ }^{1}$ Department of Physics and Astronomy, University of Leicester, Leicester LE1 7RH, UK \\ ${ }^{2}$ UNIS, P.O. Box 156, N-9170 Longyearbyen, Norway \\ ${ }^{3}$ Department of Physics, University of Oslo, P O Box 1048 Blindern, N-0316 Oslo, Norway \\ ${ }^{4}$ Queen Mary and Westfield College, University of London, London E1 4NS, UK
}

Received: 29 September 1997 / Revised: 25 August 1998 / Accepted: 4 September 1998

\begin{abstract}
The dynamics of the cusp region and postnoon sector for an interval of predominantly IMF $B_{\mathrm{y}}, B_{\mathrm{z}}$ $<0 \mathrm{nT}$ are studied with the CUTLASS Finland coherent HF radar, a meridian-scanning photometer located at Ny Ålesund, Svalbard, and a meridional network of magnetometers. The scanning mode of the radar is such that one beam is sampled every $14 \mathrm{~s}$, and a $30^{\circ}$ azimuthal sweep is completed every 2 minutes, all at $15 \mathrm{~km}$ range resolution. Both the radar backscatter and red line $(630 \mathrm{~nm})$ optical observations are closely colocated, especially at their equatorward boundary. The optical and radar aurora reveal three different behaviours which can interchange on the scale of minutes, and which are believed to be related to the dynamic nature of energy and momentum transfer from the solar wind to the magnetosphere through transient dayside reconnection. Two interpretations of the observations are presented, based upon the assumed location of the open/closed field line boundary (OCFLB). In the first, the OCFLB is co-located with equatorward boundary of the optical and radar aurora, placing most of the observations on open field lines. In the second, the observed aurora are interpreted as the ionospheric footprint of the region 1 current system, and the OCFLB is placed near the poleward edge of the radar backscatter and visible aurora; in this interpretation, most of the observations are placed on closed field lines, though transient brightenings of the optical aurora occur on open field lines. The observations reveal several transient features, including poleward and equatorward steps in the observed boundaries, "braiding" of the backscatter power, and 2 minute quasi-periodic enhancements of the plasma drift and optical intensity, predominantly on closed field lines.
\end{abstract}

Key words. Ionosphere (auroral ionosphere; plasma convection) - Magnetospheric physics (magnetopause, cusp, and boundary layers).

Correspondence to: S. E. Milan

\section{Introduction}

The cusp (see the review papers of Lockwood (1991) and Smith and Lockwood (1996), and references therein) is that region where entry of magnetosheath plasma into the magnetosphere, and hence the transport of mass, energy, and momentum from the solar wind into the near-Earth environment, is facilitated by reconnection at the dayside magnetopause. While the relative importance of quasi-continuous reconnection or more transient and intermittent "flux transfer events" (Russell and Elphic, 1978; Haerendel et al., 1978; Paschmann et al., 1982; Saunders et al., 1984; Lockwood, 1991) is as yet unclear, there is a considerable body of evidence to suggest that the auroral signature of the cusp and the ionospheric convection excited by dayside reconnection are pulsed (e.g. Feldstein and Starkov, 1967; Vorobjev et al., 1975; Horwitz and Akasofu, 1977; van Eyken et al., 1984; Goertz et al., 1985; Lockwood et al., 1989a, 1989b, 1993b, 1993c; Sandholt et al., 1985, 1986, 1989; Sandholt, 1988; Elphic et al., 1990; Fasel et al., 1992; Pinnock et al., 1993, 1995; Moen et al, 1995, 1996; Øieroset et al., 1996). Much theoretical work has been published on the ionospheric convection response to transient dayside reconnection (e.g. Southwood, 1985, 1987; Siscoe and Huang, 1985; Lee, 1986; Cowley, 1986; Southwood et al., 1988; Scholer, 1988; Wei and Lee, 1990; Lockwood et al., 1990; Cowley et al., 1991; Cowley and Lockwood, 1992; Cowley et al., 1992; Lockwood and Cowley, 1992; Rodger and Pinnock, 1997). However, the dynamics of the cusp region are still largely unclear.

The present study examines the ionospheric convection flow measured by the CUTLASS Finland HF radar in the vicinity of the cusp aurora observed by a meridian-scanning photometer located at Ny Alesund, Svalbard. Supporting observations are provided by IMAGE magnetometer stations from northern Scandinavia and interplanetary magnetic field measurements 
from the WIND spacecraft. This study is interesting from two perspectives, both in terms of cusp region dynamics as well as in understanding the processes that lead to irregularity formation, and hence coherent radar backscatter, at the ionospheric footprint of the cusp.

\section{Experimental arrangement}

The SuperDARN coherent HF radars (Greenwald et al., 1995) employ backscatter from high latitude fieldaligned ionospheric plasma density irregularities (radar aurora) as tracers of the bulk plasma motion under the influence of the convection electric field, and hence as a diagnostic tool for the investigation of large-scale magnetospheric-ionospheric coupling. The Co-operative UK Twin Located Auroral Sounding System (CUTLASS) forms the eastern-most pair of radars of SuperDARN, of which the Finland radar, located at Hankasalmi $\left(62.3^{\circ} \mathrm{N}, 26.6^{\circ} \mathrm{E}\right)$, is the focus of the present study.

The CUTLASS Finland radar usually sounds sequentially along 16 beams separated by approximately $3.2^{\circ}$ of azimuth, distributed symmetrically about the radar boresite of $-12^{\circ}$ (i.e. west of geographic north). In the present study, the radar scanned through beams 12 to 5 in descending order, returning to beam 9 between each (i.e. beams 12, 9, 11, 9, 10, 9, 9, 9, 8, 9, 7, 9, 6, 9, 5, 9), with a dwell time of $7 \mathrm{~s}$, producing a field-of-view map of backscatter every 2 minutes. Beam 9 had a sampling time resolution of $14 \mathrm{~s} .75$ range gates were sampled for each beam, with a pulse length of $100 \mu \mathrm{s}$, corresponding to a gate length of $15 \mathrm{~km}$, and a lag to the first gate of $8700 \mu \mathrm{s}(1305 \mathrm{~km})$. Fig. 1 illustrates the location of the field-of-view of the CUTLASS Finland radar for this experiment. The statistical location of the auroral oval (Feldstein and Starkov, 1967; Holzworth and Meng, 1975) at 0930 UT is also shown in Fig. 1 for quiet geomagnetic conditions $\left(K_{\mathrm{p}}=1\right)$. A 7 pulse scheme is transmitted, and analysis of the auto-correlation function (ACF) of the returned signals yields backscatter Doppler spectra, from which the spectral characteristics of power, line-of-sight Doppler velocity and spectral width can be derived. The Doppler velocity gives an estimate of the radar line-of-sight component of the plasma convection velocity.

The Meridian-Scanning Photometer (MSP) located at $\mathrm{Ny}$ Allesund $\left(78.9^{\circ} \mathrm{N}, 11.9^{\circ} \mathrm{E}\right)$, Svalbard, scans roughly along the magnetic meridian, $35^{\circ}$ west of geographic north, to $10^{\circ}$ above the northern and southern horizons, with a scan period of $18 \mathrm{~s}$. The meridian closely follows beam 9 of the CUTLASS Finland radar (see Fig. 1). The line-of-sight intensities of $630 \mathrm{~nm}$ (red line) auroral emissions are measured, corresponding to transitions from the 1D metastable state of atomic oxygen (OI). These auroral emissions can have an altitude of peak emission intensity between $250 \mathrm{~km}$ and $550 \mathrm{~km}$, excited by electrons of energies of order $100 \mathrm{eV}$. In the present study, an emission altitude of $250 \mathrm{~km}$ is assumed.

Seven IMAGE magnetometer stations are also included in the study. The stations NAL, HOR, BJN, SOR, MAS, and MUO form a meridional chain, and the station HOP is located between HOR and BJN in

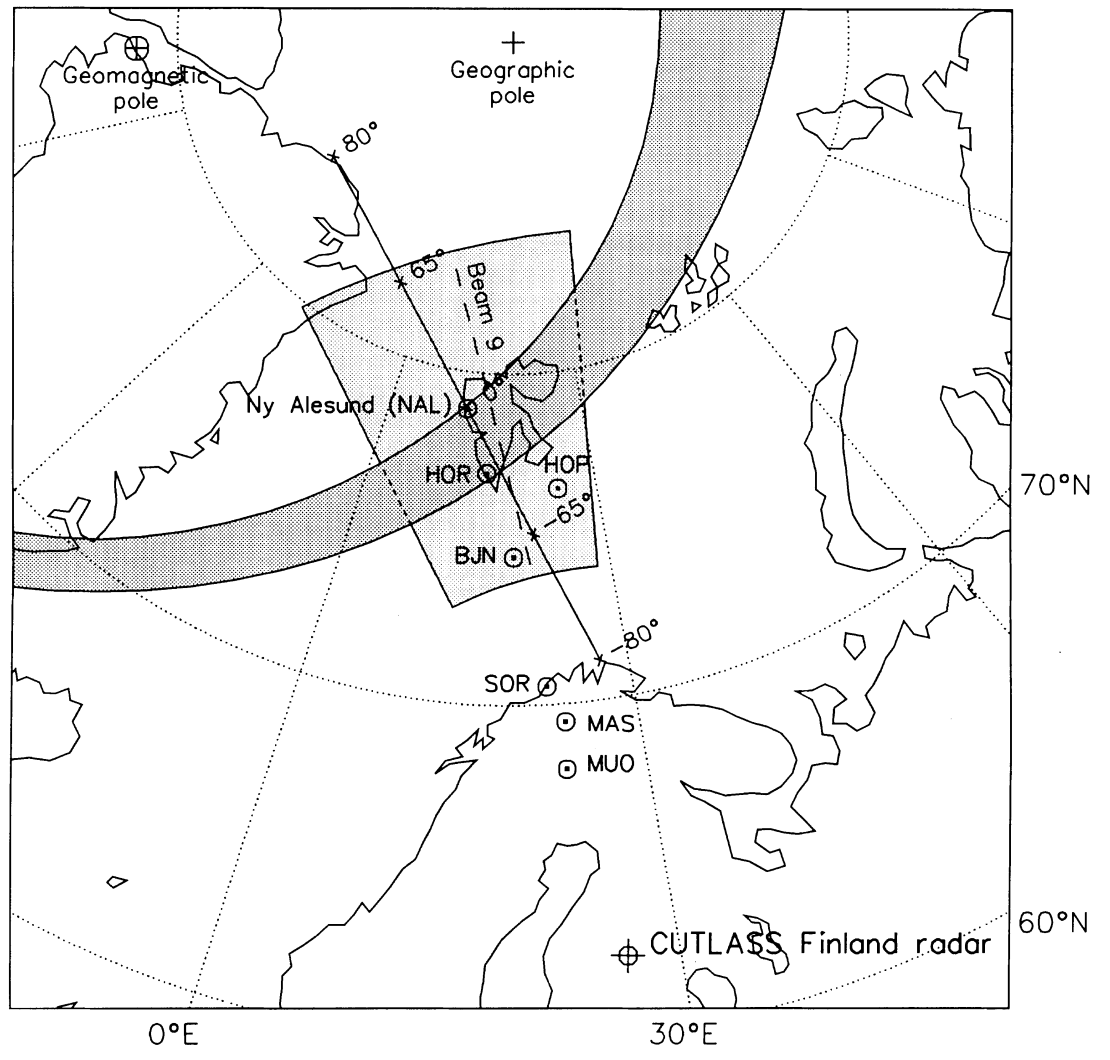

Fig. 1. The locations of the field-of-view of the CUTLASS Finland radar (beam 9 is explicitly indicated) and the meridian of the Ny Alesund MSP, projected to $250 \mathrm{~km}$ altitude. Numbers to the right of the MSP meridian indicate the location of the projection of zenith angles $0^{\circ}, 65^{\circ}$ and $80^{\circ}$. The locations of the IMAGE magnetometer sites at NAL, HOR, HOP, BJN, SOR, MAS, and MUO are indicated. Also illustrated for reference is the statistical location of the quiet $\left(K_{\mathrm{p}}=1\right)$ auroral oval at $0930 \mathrm{UT}$ 
latitude and approximately $250 \mathrm{~km}$ to the east of the chain (see Fig. 1).

\section{Observations}

During the interval considered in the present study, 0840 UT to 1030 UT on 17 December 1995, the Ny Alesund MSP, the CUTLASS Finland radar, and the IMAGE magnetometers were located near local noon and in the early post-noon sector, and provided information regarding the ionospheric footprint of the magnetospheric cusp. Solar wind and interplanetary magnetic field (IMF) observations from the WIND spacecraft provide a context within which the behaviour of the ionospheric cusp region can be investigated.

\subsection{Solar wind and IMF observations}

During the interval of study the WIND spacecraft was located upstream of the magnetosphere at $\left(\mathrm{X}_{\mathrm{GSM}}\right.$, $\left.\mathrm{Y}_{\mathrm{GSM}}, \mathrm{Z}_{\mathrm{GSM}}\right) \approx\left(59 R_{\mathrm{e}}, 32 R_{\mathrm{e}}, 0 R_{\mathrm{e}}\right)$. WIND measurements of the solar wind dynamic pressure and the three GSM components of the IMF, $B_{\mathrm{x}}, B_{\mathrm{y}}$, and $B_{\mathrm{z}}$, are illustrated in Fig. 2 for the interval 0824 UT to 1014 UT. A rotation of the IMF was observed near $0845 \mathrm{UT}$, associated with a $40 \%$ increase in the solar wind dynamic pressure. Subsequently, the southward component of the IMF, $B_{z}$, remained predominantly negative, though decreasing in magnitude; $B_{y}$ remained negative for the rest of the interval of study.

An approximate solar wind velocity of $420 \mathrm{~km} \mathrm{~s}^{-1}$ measured by the spacecraft during this interval gives a delay of some 12 minutes between the observation of IMF features by WIND and their incidence on the Earth's bow-shock. Various assumptions can be made regarding the subsequent travel-time of the shocked solar wind across the magnetosheath and the Alfvén travel-time for occurrences at the magnetopause to be transmitted to the ionospheric footprint of the cusp, giving an overall estimated delay of some 16 to 24 minutes.

\subsection{Radar and MSP observations}

The MSP observations of the red line intensity for the study interval are illustrated in Fig. 3, as a function of zenith angle and time, from 0800 UT to 1100 UT.

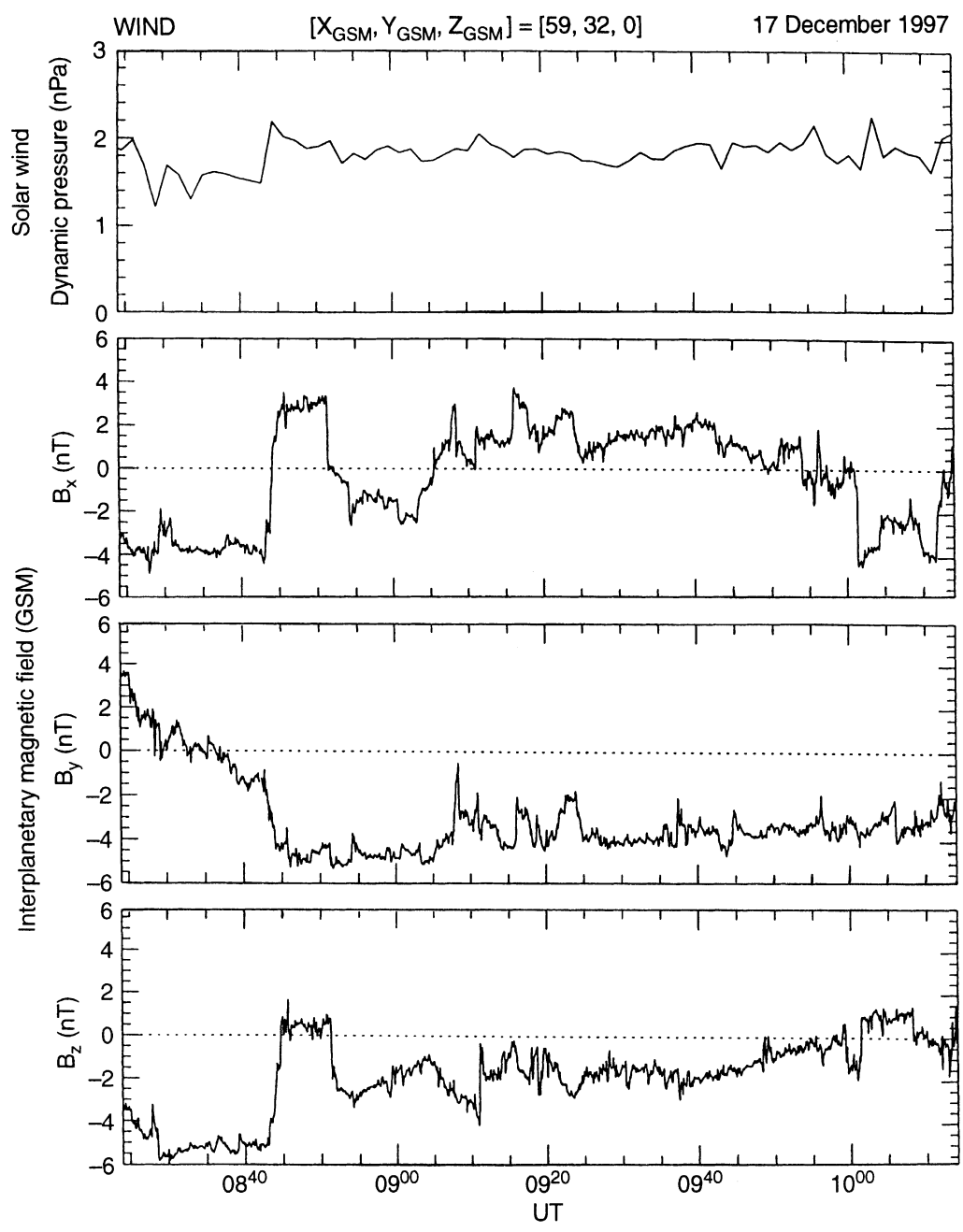

Fig. 2. Time series of the solar wind dynamic pressure and the GSM components of the IMF, $B_{\mathrm{x}}, B_{\mathrm{y}}$, and $B_{\mathrm{z}}$, observed by the WIND spacecraft for 0824 UT to 1014 UT, 17 December 1995 

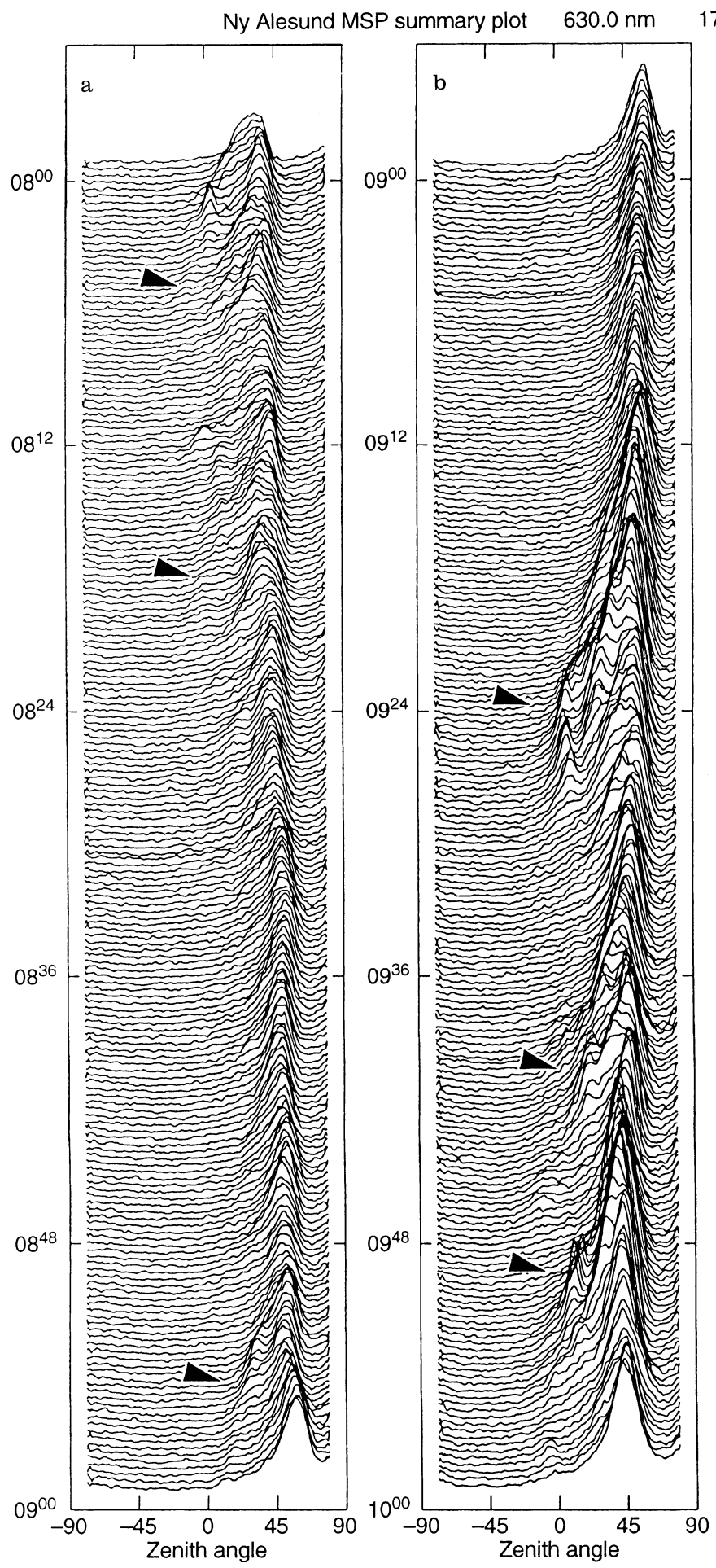

Throughout the interval, a persistent or continuous arc is observed near $45^{\circ}$ zenith angle, though this moves poleward after 1000 UT. The intensity of this arc, initially $1.5 \mathrm{kR}$, increases to $2.5 \mathrm{kR}$ near $0900 \mathrm{UT}$ and again to $5 \mathrm{kR}$ after $0915 \mathrm{UT}$, after which the intensity varies considerably between $2.5 \mathrm{kR}$ and $5 \mathrm{kR}$. In addition to the continuous arc, very faint polewardmoving forms are observed between 0800 UT and 0900 UT; three such features are indicated by arrows in panel $a$ of Fig. 3. After 0915 UT, these forms appear more as
17 December 1995

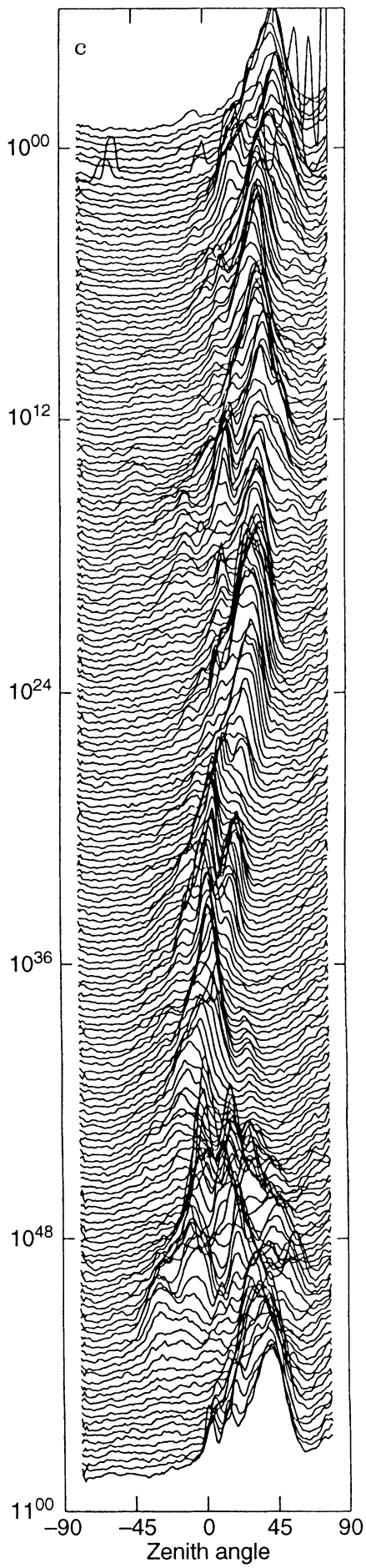

Fig. 3. The Ny Ålesund MSP $630 \mathrm{~nm}$ (red line) optical emission intensity as a function of zenith angle $\left(-90^{\circ}\right.$ to the north, $90^{\circ}$ to the south) and UT, between $08 \mathrm{UT}$ and $11 \mathrm{UT}, 17$ December 1995. Vertical tick marks are equivalent to $1.5 \mathrm{kR}$ emission intensity. Arrows in panel $a$ indicate the times of three poleward-moving auroral forms. Arrows in panel $b$ indicate the times of three transient brightenings of the aurora poleward of the continuous arc (see Fig. 4 for the identification of other transient brightenings)

stationary auroral brightenings near the poleward edge of the main optical arc; three such features are indicated in panel $b$ of Fig. 3 .

The CUTLASS Finland radar observations from beam 9 , the high time-resolution beam, for the study interval are presented in Fig. 4. The top three panels indicate the radar backscatter power (signal-to-noise ratio), line-of-sight velocity and spectral width. Positive (negative) line-of-sight velocities are towards (away from) the radar. Vertical power drop-outs, especially 
after $1000 \mathrm{UT}$, are associated with HF interference. Low power, low velocity and low spectral width backscatter observed at the very nearest ranges between 0840 UT to 0915 UT and 1000 UT to 1020 UT is ground backscatter and can be ignored. Similar backscatter observed above $79^{\circ} \mathrm{N}$ between 0925 UT and 1020 UT is shown by interferometric techniques (see Milan et al., 1997) to have a different elevation angle distribution from the rest of the observations and is almost certainly ground backscatter also; this backscatter region will not be considered further. The bottom panel of Fig. 4 illustrates the red line optical emission intensity along the MSP meridian (i.e. the same data as presented in Fig. 3), projected to an emission altitude of $250 \mathrm{~km}$. Superimposed on the radar observations is the latitude of the peak red line emission intensity and the latitudes at which the red line emission intensity falls to $1.5 \mathrm{kR}$ poleward and equatorward of the peak. Vertical dashed lines in Fig. 4 indicate times at which the behaviour of the observations appears to change markedly. The intervals between dashed lines have been numbered I to VII to aid description in the following discussion. The occurrences of transient brightenings of the optical aurora poleward of the continuous arc are marked in the bottom panel by white arrows.

During interval I only sporadic radar backscatter and low intensity optical emission is observed. The amount of backscatter observed by the radar and the intensity of the optical emission increases significantly at the start of interval II, $0900 \mathrm{UT}$; significant radar and optical aurora continue to be observed until after $1100 \mathrm{UT}$. During this period there is a general poleward migration of the aurora, from near $74^{\circ}$ to $77^{\circ}$ geomagnetic latitude. In general there is excellent correspondence between the locations of the radar and optical cusp aurora, in particular at their equatorward boundary, and especially during intervals II to V. To illustrate the degree of co-location of the equatorward boundaries of the optical emission and radar backscatter, Fig. 5 presents the latitudinal variation in the equatorward iso-contours of $1.5 \mathrm{kR}$ red line emission intensity and 10 dB backscatter power, between 0855 UT and 1000 UT. Even during intervals when the contours are separated in latitude (in general by no more than $0.5^{\circ}$ ) their motions are in tandem. A correlation coefficient of 0.90 is found between the locations of the two boundaries, as illustrated in the inset panel of Fig. 5, in which the dotted line is a least squares fit to the distribution, with a gradient of 1.01. The separation in latitude of the contours appears to increase somewhat throughout the interval presented, perhaps as a consequence of a gradual variation in the peak emission altitude of the aurora or of a change in the propagation environment of the radar.

In the period of most interest to the present study, intervals II to VI, the observations cycle through two modes of behaviour, which will hereafter be refered to as states 1 and 2. State 1, intervals III and V, is characterised by high red line optical intensities, a peak intensity above $3.5 \mathrm{kR}$, and radar line-of-sight velocities which are positive at lower latitudes and negative at higher latitudes. State 2, intervals II, IV and VI, is characterised by lower red line optical intensity, a peak intensity in general below $3.5 \mathrm{kR}$, and radar line-of-sight velocities which are negative at all latitudes. These two states will be described in more detail below.

\subsubsection{State 1 (intervals III and V)}

The high time resolution radar observations (Fig. 4) indicate that in state 1 the radar backscatter is contained almost entirely within the higher and lower latitude 1.5 $\mathrm{kR}$ red line contours. The radar line-of-sight velocities are structured in latitude, generally positive at lower latitudes and negative at higher latitudes. Spatial maps of the line-of-sight velocity from these intervals indicate that the flow is predominantly azimuthal during these intervals, and that a flow reversal is present, flow being directed westward at lower latitudes and eastward at higher latitudes. Fluctuations in the sign of the line-ofsight velocities observed in Fig. 4 during these intervals are caused by small variations in the angle of flow relative to the nearly polewards-directed beam 9 .

The onset of state 1 flow behaviour, the beginning of intervals III and V, is accompanied by the appearance of a new peak in the backscatter power at a latitude below that of the pre-existing peak (see 0914 UT and 0950 UT, Fig. 4). This occurs also at 0921 UT, during on-going state 1 behaviour. This feature will hereafter be termed "braiding" as in some cases the pre-existing peak in the backscatter power migrates poleward prior to the appearance of the second peak, as at 0914 UT and 0921 UT. During state 1, when two backscatter intensity peaks are present, the central minimum appears at the latitude of the flow reversal, also close to the latitude of the peak in the red line optical intensity. A similar latitudinal structure is observed in the spectral width measurements during state 1 , higher spectral widths being co-located with the peaks in backscatter intensity (see esp. interval III).

\subsubsection{State 2 (intervals II and IV)}

During state 2, the line-of-sight velocities in the high time resolution observations become exclusively negative. Spatial maps from these intervals suggest that the plasma drift continues to display a general azimuthal flow, eastward and westward at higher and lower latitudes, respectively. However, the state 2 plasma drift velocity is significantly structured in time, with recurrent velocity enhancements moving rapidly poleward (see esp. interval IV, Fig. 4). These velocity enhancements are quasi-periodic in nature, with a recurrence period comparable with the radar scan period and hence the radar scan has insufficient temporal resolution to properly resolve these features. Transient enhancements are also present in the red line emission intensities during state 2 (esp. intervals IV and VI). To investigate the relationship between these optical and plasma drift 

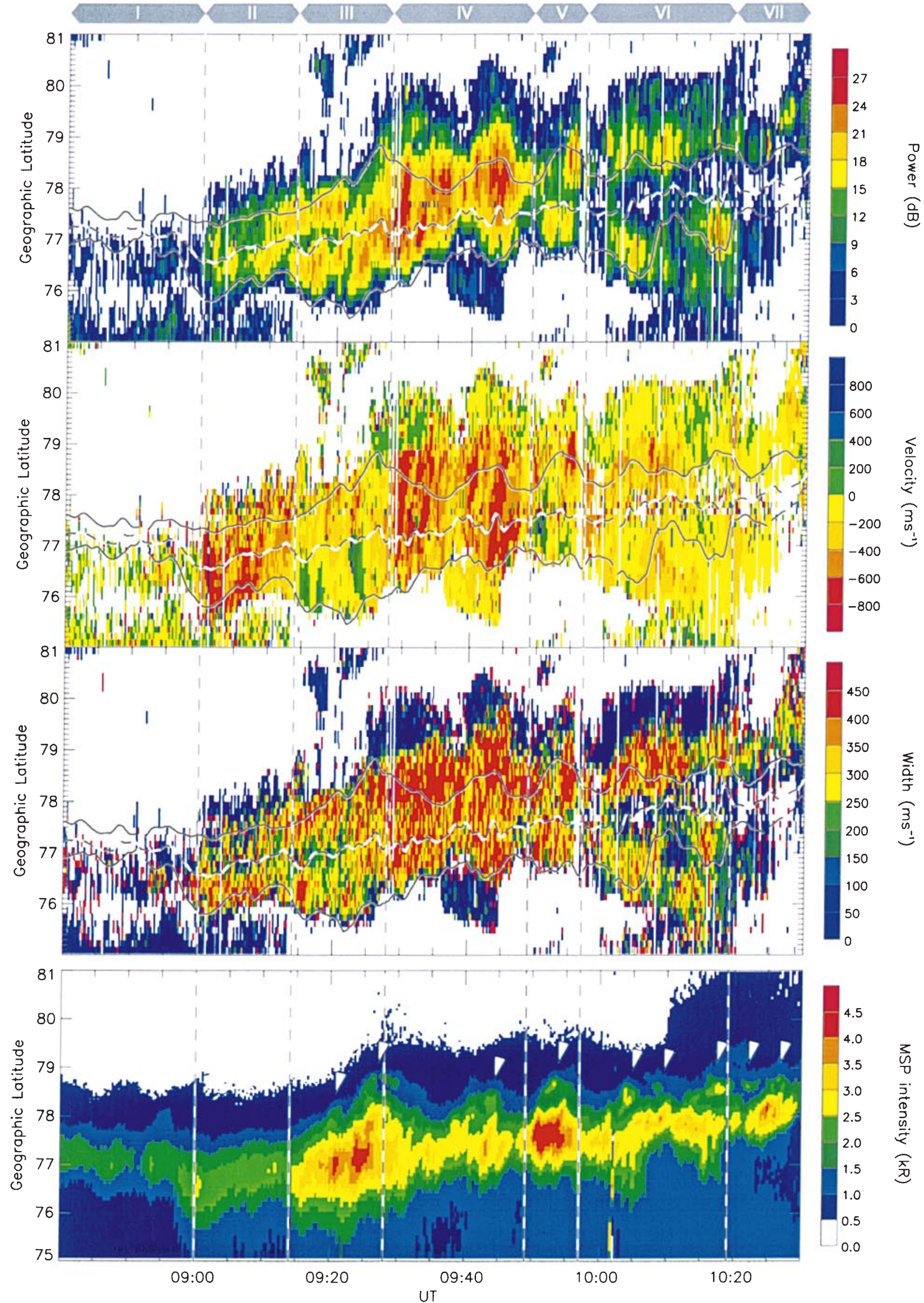
Fig. 4. The backscatter power (top panel), line-of-sight velocity (second panel), and spectral width (third panel) observations along beam 9 of the CUTLASS Finland radar for the period 0840 UT to 1030 UT. Positive (negative) velocities indicate motion towards (away from) the radar. Also illustrated for the same period is the $630 \mathrm{~nm}$ (red line) optical emission intensity observed by the Ny Ålesund MSP, projected to an assumed emission altitude of $250 \mathrm{~km}$. White arrows indicate the times of transient brightenings of the aurora poleward of the continuous arc. Superimposed on the radar data are, in order of increasing latitude, the locations of the equatorwards $1.5 \mathrm{kR}$ isocontour, the peak intensity, and the polewards $1.5 \mathrm{kR}$ iso-contour of the red line emission. The latitude range of the panels, $75^{\circ} \mathrm{N}$ to $81^{\circ} \mathrm{N}$, corresponds to the geomagnetic latitude range $72.6^{\circ}$ to $78.5^{\circ}$ CGMLAT

transients, Fig. 6 presents a more detailed comparison of the velocity and optical measurements. The top panel of Fig. 6 illustrates the line-of-sight radar velocities, on a scale from $0 \mathrm{~m} \mathrm{~s}^{-1}$ to $-1000 \mathrm{~m} \mathrm{~s}^{-1}$ (i.e. away from the radar only). The bottom panel indicates the optical emission intensity of the red line, projected to an assumed emission altitude of $250 \mathrm{~km}$. Superimposed on both panels are 10 diagonal dashed lines, indicating a fit-by-eye to the poleward-moving features, based primarily on the optical observations. In most of the 10 cases there is an excellent agreement between the location and motion of the poleward-moving optical features and the poleward-moving velocity enhancements. The lower-latitude boundary of the velocity enhancements matches well the lowest latitudes at which the intensifications in the red line emission are observed. However, the transients are observed to continue to higher latitudes in the radar data than in the optical measurements. The velocity and optical intensity enhancement features have a lifetime and recurrence period of approximately 2 minutes.

\subsection{Magnetometer observations}

Fig. 7 illustrates magnetograms ( $\mathrm{X}$ and $\mathrm{Y}$ components) for the study interval from the 7 IMAGE stations. The magnetograms for the interval 0855 UT to 0910 UT (i.e. spanning the transition from interval I to interval II) from the stations NAL, HOR, HOP, and BJN indicate a positive (negative) bay in the $\mathrm{X}$ component of stations equatorward (poleward) of HOP and a negative-thenpositive bipolar signature in the $\mathrm{Y}$ component of all the stations. Such signatures have been identified with "travelling convection vortices" or TCVs (Friis-Christensen et al., 1988), but this signature is also consistent with a variation in the intensity of a FAC sheet located near the latitude of HOP (approximately $76^{\circ} \mathrm{N}$ ). The transition from interval III to interval IV (approximately 0926 UT to 0930 UT) is again marked a similar, though less intense, magnetic signature, the centre being located this time between the latitudes of NAL and $\operatorname{HOR}\left(78^{\circ} \mathrm{N}\right)$.

\section{Discussion}

\subsection{General morphology and IMF dependence of the dayside aurora}

The degree of co-location of the optical red line and radar aurora is impressive (see also Rodger et al., 1995), especially at their equatorward boundary. This colocation suggests that the precipitation responsible for the excitation of the optical aurora is also a major source of the energy leading to the generation of the ionospheric irregularities from which the radar scatters. The source of this precipitation, however, has to be considered carefully.

Red line aurora are often observed poleward of the dayside auroral oval (Whalen et al., 1971; Murphree et al., 1980; Elphinstone et al., 1992), such emissions being excited by low energy (of order $100 \mathrm{eV}$ ) electrons consistent with the energy characteristics of unaccelerated magnetosheath plasma of cusp/cleft origin - on newly-opened field lines (Lockwood et al., 1993a; Sandholt et al., 1996). Hence, the equatorwards boundary of the red line aurora could be related to the

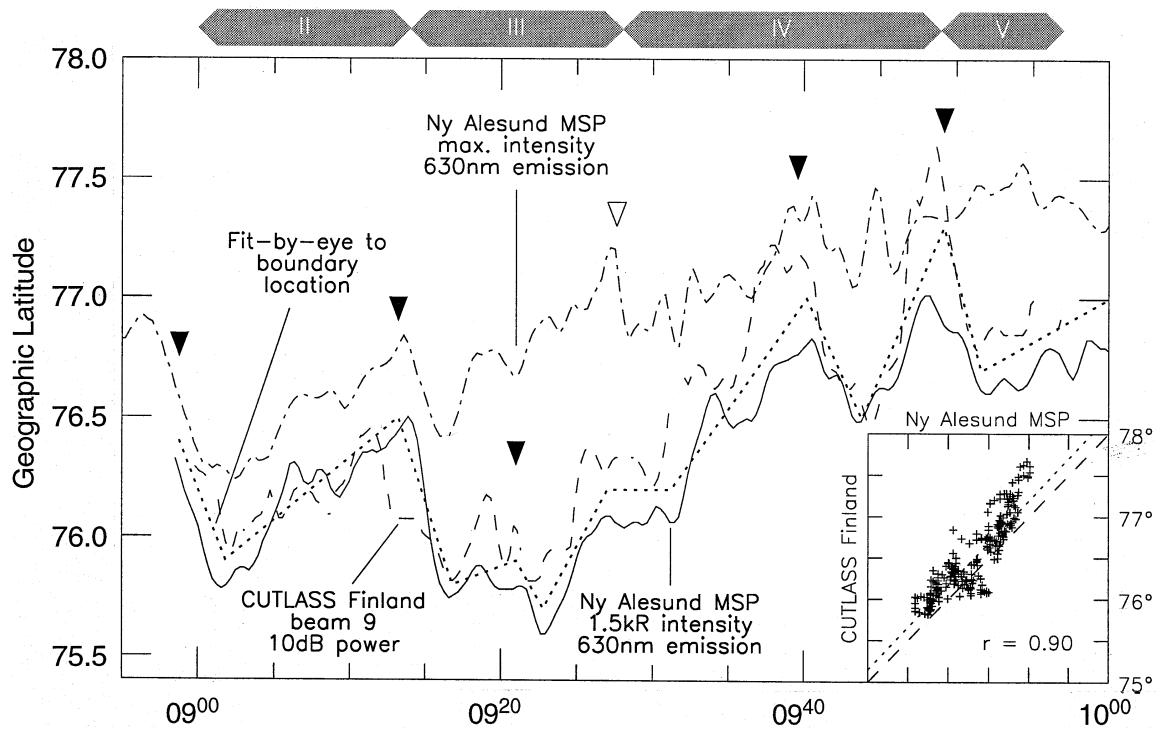

Fig. 5. The locations of the equatorward boundaries of the red line optical emission (solid line) and radar backscatter (dashed line) between $0855 \mathrm{UT}$ and $1000 \mathrm{UT}$, as determined from the $1.5 \mathrm{kR}$ and $10 \mathrm{~dB}$ isocontours, respectively. The dotted line indicates an approximate fit-by-eye to the motion of these boundaries. Also included is the location of the peak in the red line optical emission (dot-dashed line). Arrows indicate the approximate times of the occurrence of equatorward steps of the radar and optical aurora. The inset panel indicates the correspondence between the latitudes of the equatorward boundaries of the radar and optical aurora, for the period illustrated 

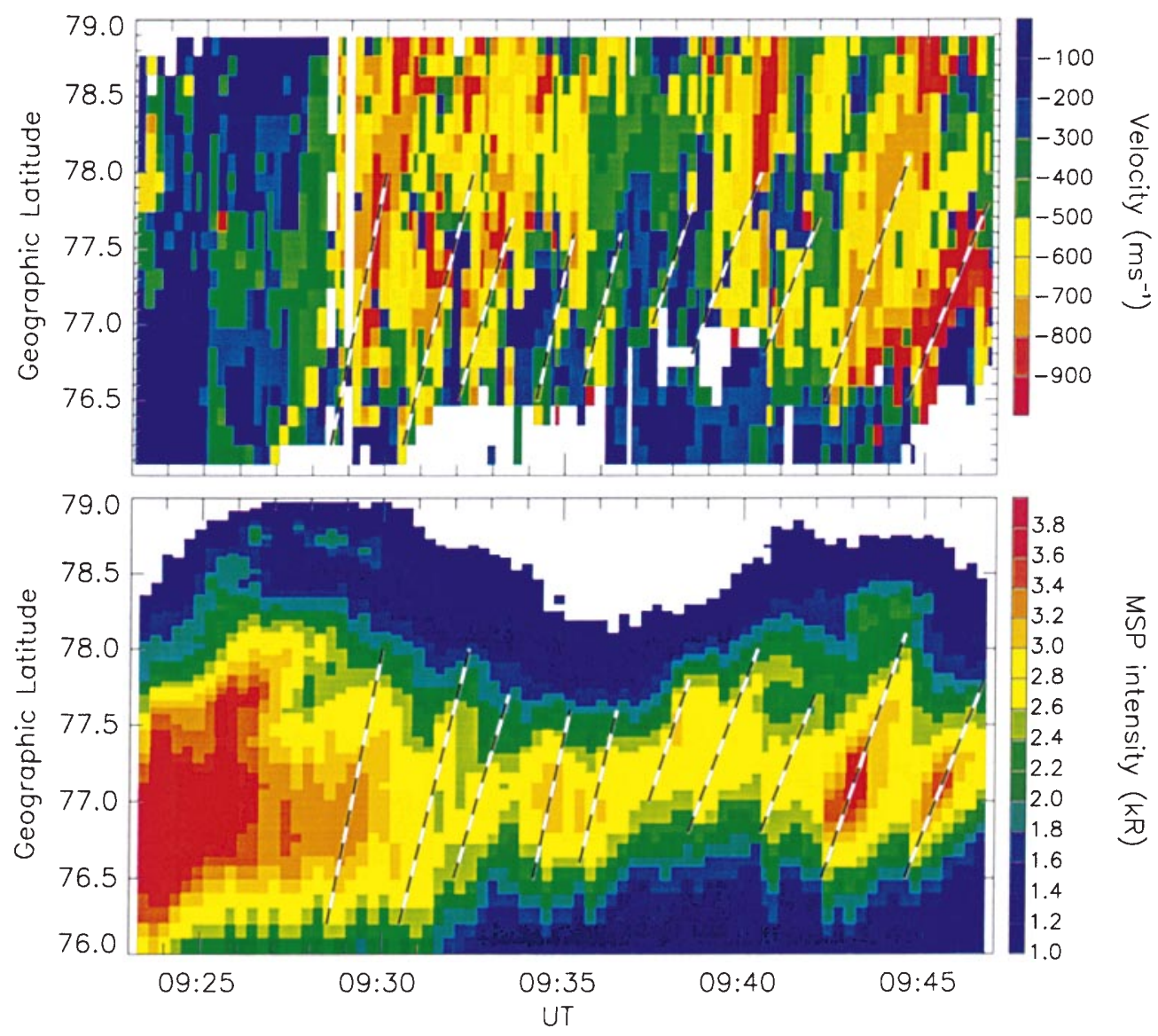

Fig. 6. Radar and MSP observations of the period 0923 UT to 0947 UT (end of interval III and interval IV). (a) Line-of-sight plasma drift velocities along beam 9 (note: the scale involves negative velocities only). (b) Red line optical emission intensities projected to $250 \mathrm{~km}$. The dashed lines in both panels are fits-byeye to the optical polewardmoving optical transients and the radar flow bursts location of the open/closed field line boundary or OCFLB.

However, other sources of precipitation are also present in the dayside high latitude ionosphere, especially in the pre- and post-noon sectors, for instance the low latitude boundary layer (LLBL) and boundary plasma sheet (BPS) precipitation on closed field lines which constitute the region 1 field-aligned current system (Potemra, 1994). In the post-noon sector, where most of the present observations are made, the region 1 FAC is directed upwards. This LLBL/BPS precipitation, as identified by DMSP particle measurements, gives rise to "cleft aurora", a persistant or continuous band of red line emission, associated with sunward plasma drift (Sandholt et al., 1993); such aurora were labeled "type 7" by Sandholt et al. (1998). Poleward of the cleft aurora is observed mantle precipitation, associated with antisunward plasma drift (Sandholt et al., 1993). This mantle precipitation occurs on newly-opened field lines which are a few minutes old, and hence which have convected some distance from the cusp region. It is this precipitation which is associated with auroral brightenings poleward of the cleft aurora. Hence an alternative interpretation of the present observations, certainly after 0915 UT, is of continuous cleft aurora on closed field lines at the lower latitudes, and transient auroral brightenings associated with precipitation on open field lines at higher latitudes; three such auroral brightenings are indicated in panel $b$ of Fig. 3. The OCFLB is, then, placed near the poleward edge of the continuous red line aurora, but equatorward of the transient brightenings.

It is possible that both of the above scenarios are observed during the present interval. Prior to 0900 UT, interval I, the red line aurora and radar backscatter are perhaps associated with the cusp-proper, in a configuration known as the "midday gap" - low red line optical intensity, sometimes associated with poleward-moving auroral forms, as indicated in panel $a$ of Fig. 3. After this time, at the beginning of interval II, the appearance of the region 1 current system equatorward of the cusp/ mantle precipitation gives rise to an increase in the intensity and latitudinal extent of the optical and radar aurora. The change in the auroral configuration at the beginning of interval II appears to be a consequence of the rotation of the IMF direction observed by the WIND spacecraft near $0840 \mathrm{UT}$. The $B_{\mathrm{z}}$ component of the IMF remains southward or near-zero throughout the interval, but there is a swap in the east-west component from $B_{\mathrm{y}}>0 \mathrm{nT}$ to $B_{\mathrm{y}}<0 \mathrm{nT}$. This change impinges on the dayside magnetopause after a solar wind delay from the WIND location of some 16 to 24 minutes, i.e. near 0900 UT. The ionospheric footprint of the dayside merging line then moves from the post- to pre-noon sector under the influence of IMF $B_{\mathrm{y}}$, and a post-noon auroral configuration is established overhead the radar and MSP.

Also at this time, a sudden compression of the magnetosphere is expected, due to step in the solar wind 

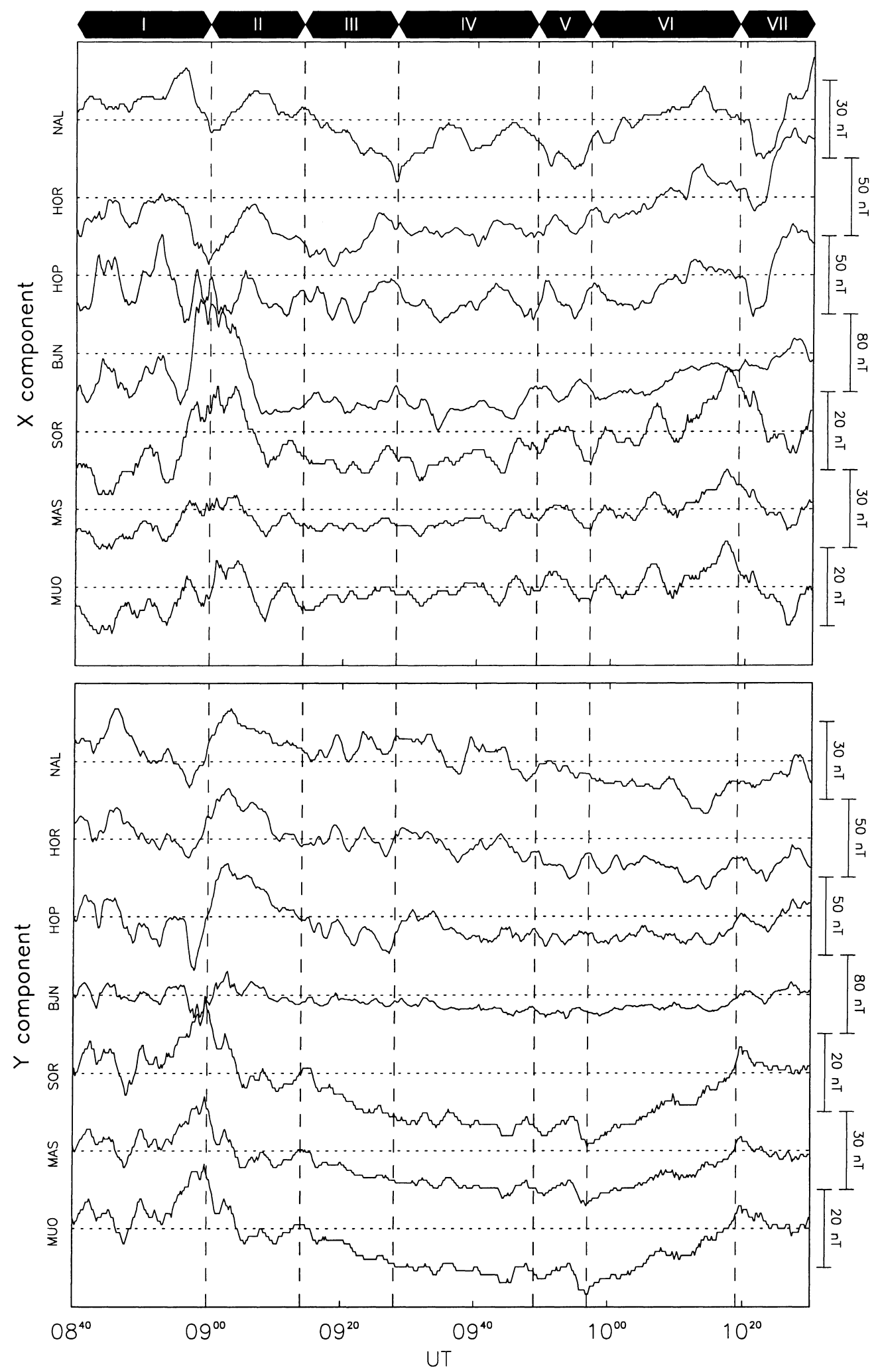

Fig. 7. $\mathrm{X}$ and $\mathrm{Y}$ component magnetograms from the IMAGE stations NAL, HOR, HOP, BJN, SOR, MAS, and MUO, for the period 0840 UT to 1030 UT on 17 December 1995

dynamic pressure observed at $0843 \mathrm{UT}$, near the time of the IMF rotation. Such pressure changes are known to give rise to "travelling convection vortices" or TCVs (e.g. Friis-Christensen et al., 1988), similar to that observed in the magnetograms between 0855 UT and 0910 UT (see Sect. 3.3 and Fig. 7). It is just as reasonable to suggest, however, that the observed magnetic deflections are associated with the motion and intensification of the FAC systems associated with the change in IMF $B_{\mathrm{y}}$. As no other significant pressure variations were observed during the present study, all subsequent variations in the auroral behaviour must be 
produced by variations in the IMF, including the TCVlike signature observed between intervals III and IV (see Sect. 3.3).

The plasma flow and optical behaviour observed after 0900 UT appears to interchange between two characteristic states. In both a flow shear is evident near the latitude of the peak of the optical intensity. However, in state 2 there appears to be a significant poleward flow component superimposed on this flow reversal pattern. Possibly, the switch between the two states is due to the motion overhead of the convection pattern as a whole, under the influence of the orientation of the IMF. In this case, the two states would, perhaps, represent observations from two different points within the convection pattern, in state 2 a view near the throat of the convection pattern where polewards flow is expected, and in state 1 a view further around the dusk convection cell where a flow reversal is expected. However, a brief examination of the IMF clock angle does not reveal any obvious precursors of the interchange between auroral states. Unfortunately, a more detailed analysis of the cusp auroral response to changes in the IMF is not possible due to the uncertainty in the delay between WIND observations of the IMF and their impact on the dayside ionosphere.

\subsection{Motions of the open/closed field line boundary}

A knowledge of the location and motion of the ionospheric footprint of the open/closed field line boundary is important for magnetospheric studies. In general the OCFLB is "adiaroic" (Siscoe and Huang, 1985) and there is no plasma flow across this boundary. During periods of dayside reconnection, previously closed field lines are opened to form a region of newly-opened flux. At this time a portion of the OCFLB, the "merging line," becomes non-adiaroic and plasma moves relative to the boundary due to the reconnection electric field. Determining the length of the merging line and the magnitude of the reconnection electric field allows the contribution of dayside reconnection to the cross polar cap potential to be estimated (e.g. Baker et al., 1997). In general, the true location of a non-adiaroic OCFLB should lie equatorward of the equatorward boundary of cusp precipitation. This is a consequence of the non-zero travel-time of the most energetic magnetosheath particles from the magnetopause reconnection site to the ionosphere, during which time the newly-opened flux tubes are convecting poleward under the influence of the reconnection electric field (Rodger and Pinnock, 1997). However, if no reconnection is taking place at the point of observation - as is the case outside of the cusp region proper, i.e. after the start of interval II - the reconnection electric field is zero and the boundary motion and ionospheric flow are equal.

In the following discussion, the equatorward boundary of the radar and optical aurora will be assumed to be a proxy for the location of the OCFLB. The OCFLB may be displaced some distance poleward of this auroral boundary, esp. if the equatorward portion of the auroral luminosity is the consequence of precipitation in the region 1 current system on closed field lines. It will be assumed, however, that this offset is approximately constant. Short timescale motions of the dayside boundary of the polar cap are assumed to be independent of substorm processes occurring on the nightside. The general polewards drift of the aurora observed between 0900 UT and 1030 UT is probably a consequence of a decrease in the area of the polar cap due to a disparity between the dayside and nightside reconnection rates, but the velocity of this motion is small in comparison to the localised perturbations produced by the dayside cusp phenomena which will now be considered.

The location of the OCFLB, as determined from the combined radar and optical observations, appears to step equatorward and retreat poleward in a quasiperiodic manner (Fig. 4 and 5). This motion is possibly related to the transient nature of dayside reconnection. A burst of reconnection - a flux transfer event or FTE appends a new region of open flux to the polar cap (e.g. Cowley and Lockwood, 1992; Cowley et al., 1992; Lockwood and Cowley, 1992), as indicated in Fig. 8(1). During the period of creation of the new open flux, the OCFLB bounding this region - the merging gap expands equatorwards, by perhaps $0.5^{\circ}$ of latitude or some $50 \mathrm{~km}$. Such equatorward motions of the OCFLB, typically with a duration of 2 to 3 minutes, are observed in the present study, for instance at 0900 UT, 0912 UT, 0921 UT, 0940 UT and 0949 UT (see Fig. 5, times marked with full arrows); there is also some evidence for an equatorward motion of the cusp aurora at 0927 UT (time marked with an open arrow). During intervals of state 1 behaviour (intervals III and V) these equatorward jumps of the OCFLB are accompanied by the appearance of new low latitude peaks in the radar backscatter - "braiding" - at 0913 UT, 0921 UT and 0950 UT.

Two forces act upon the new open flux tube (Southwood, 1985, 1987; Cowley, 1986), and hence the ionospheric plasma at its footprint: one azimuthally due to the $B_{\mathrm{y}}$ component of the IMF (Atkinson, 1972; Jørgensen et al., 1972) and the other poleward due to the antisunward magnetosheath flow (Saunders, 1989). Initially, the poleward component is negligible as the newly-opened flux tube is draped across the front of the magnetopause and slack, and the azimuthal component of the flow dominates, as in Fig. 8(2); the sense of $B_{\mathrm{y}}$ during the interval of study produces an eastward azimuthal motion. After a delay of some 5 to 8 minutes the slack in the newly-opened flux tube is taken up, and the poleward velocity component becomes increasingly significant (Cowley et al., 1992). This poleward motion acts to assimilate the new region of open flux with the pre-existing open flux of the polar cap, producing a poleward retreat of the adiaroic OCFLB, returning the system to quasi-equilibrium. This poleward motion of the OCFLB has, in the present observations, a mean velocity of order $125 \mathrm{~m} \mathrm{~s}^{-1}$. At this velocity, the OCFLB, its location initially perturbed by some $50 \mathrm{~km}$ following the burst of reconnection, can return to its equilibrium 

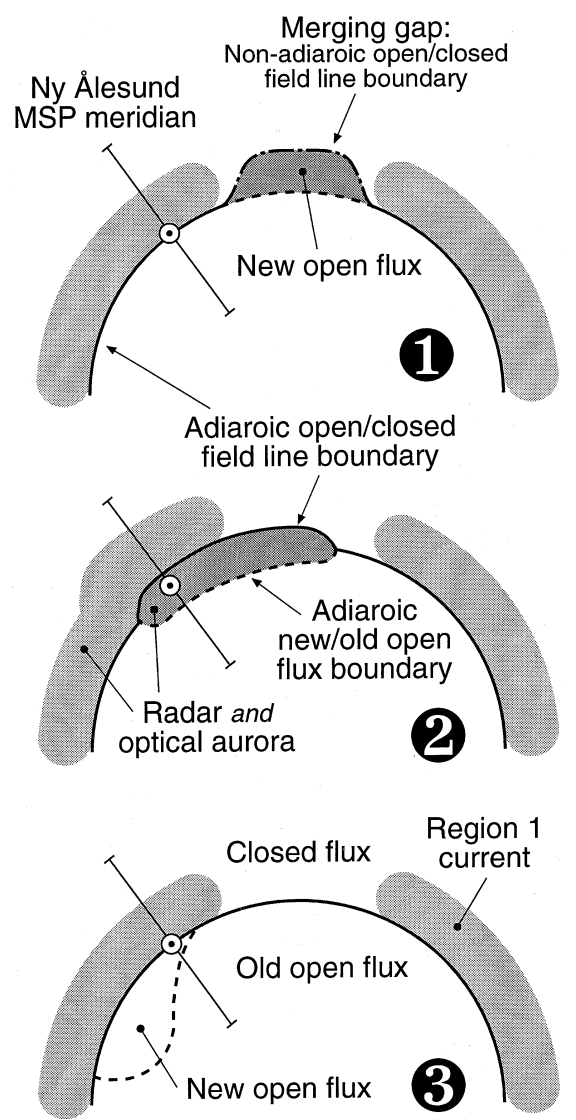

Fig. 8. A schematic diagram indicating three stages in the assimilation of a region of newly-opened flux with the old open flux of the polar cap (inside semi-circle) for $B_{\mathrm{y}}<0 \mathrm{nT}$. Local noon is at the top of the diagram and the approximate location of the MSP meridian is indicated in the post-noon sector. The solid line is the adiaroic open/ closed field line boundary. Dashed lines indicate the boundary between new and old open flux. The light grey regions in the pre- and post-noon sectors on closed field lines indicate the region 1 current location. (1) FTE footprint appended to front of polar cap at prenoon reconnection site. The dot-dashed line represents the merging gap along which reconnection is on-going. This region subsequently drifts eastwards. (2) Region of newly-opened flux drifts into radar field-of-view and an equatorward step of the equatorward boundary of the aurora is observed. (3) Newly-opened flux assimilated with polar cap, OCFLB returned to quasi-equilibrium, drift velocity becoming negligible

position in approximately 5 to 10 minutes. Once the FTE flux tube is assimilated with the old open flux of the polar cap, Fig. 8(3), the forces acting on it become negligible and the flow decays. Outside of the moving FTE flux tube footprint, ionospheric flow is produced primarily by displacement of the surrounding (incompressible) open and closed flux tubes; it is this displacement that is responsible for the excitation of convection within the polar cap and return flow at lower latitudes. The region 1 current system on closed field lines equatorward of the OCFLB will be displaced equatorward, and hence its lower latitude boundary will act as a proxy for the motion of the OCFLB; see Fig. 8(2).

The transient equatorward steps of the OCFLB are in general accompanied by the appearance of transient enhancements of the optical luminosity poleward of the main continuous region 1 current arc, most obvious at the times marked with arrows in the bottom panel of Fig. 4. These are interpreted as luminosity associated with precipitation within the region of newly opened flux as it convects eastwards across the MSP meridian. These optical transients occur within the region of antisunward (eastward) flow observed by the radar.

\subsection{Flux transfer events and shorter period transient events}

As discussed above, many of the observations of the present study can be explained in terms of flux transfer events. Magnetopause FTEs - the magnetic and particle signature of transient dayside reconnection - have a recurrence period of 8 minutes (Berchem and Russell, 1984; Rijnbeek et al., 1984), though Lockwood and Wild (1993) report an inter-FTE interval distribution which extends to periods as short as 2 to 3 minutes. Ground-based studies of the optical cusp aurora have reported poleward-moving optical transients - "dayside auroral breakups" - which propagate poleward from the red line aurora with velocities of order $0.5 \mathrm{~km} \mathrm{~s}^{-1}$ to $1 \mathrm{~km} \mathrm{~s}^{-1}$ (Feldstein and Starkov, 1967; Vorobjev et al., 1975; Horwitz and Akasofu, 1977; Sandholt et al., 1985; Sandholt, 1988; Karlson et al., 1996), associated with magnetopause FTEs (Sandholt et al., 1986; Elphic et al., 1990). These transients are visible in the green line $(557.7 \mathrm{~nm})$ as well as the red, indicating the precipitation of electrons accelerated to $\mathrm{keV}$ energies, i.e. not of cuspproper energy characteristics as defined by Newell and Meng (1988). Fasel (1995) determined that these events had a mean recurrence period of 7 minutes, though the inter-event interval distribution was highly skewed and had a mode of 3 minutes. In the present study, observations of exactly this nature are confined to interval I, see panel $a$ of Fig. 3. Previous HF radar studies of the cusp region have indicated polewardmoving velocity enhancements, major events having a recurrence period of 7 minutes, and these also have been associated with FTEs (Pinnock et al., 1995).

In the present study, the observations appear to be made predominantly to the east of the cusp proper. Equatorward steps of the low latitude boundary of the radar and optical aurora, and transient brightenings of the aurora poleward of the main persistent arc are attributed to the eastward motion of regions of newlyopened flux - each associated with an individual FTE from the cusp region and into the radar field-of-view. These observations bear similarities to other studies conducted in the post-noon sector, such as Moen et al. (1995, 1996) and Provan et al. (1998). Nine transient brightenings of the aurora are observed within the interval $0920 \mathrm{UT}$ to $1025 \mathrm{UT}$, giving an approximate mean recurrence period of just over 8 minutes, close to the recurrence periods of magnetopause FTEs (Bercham and Russell, 1984; Rijnbeek et al., 1984), of optical transients (Fasel, 1995), and of plasma drift velocity bursts (Pinnock et al., 1995). Overall it is estimated that the growth and decay of ionospheric convection flow 
associated with a single burst of reconnection has a time scale of some 10 to 15 minutes (as discussed in Sect 4.2; see also Cowley et al., 1992; Lockwood and Davis, 1996). As the recurrence rate of FTEs is of order 8 minutes, several "active" FTE footprints can exist in the dayside ionosphere simultaneously, giving a flow pattern indistinguishable from the traditional two-cell convection pattern (Lockwood, 1991).

Other, shorter-period transients are observed in the present study also. The high time resolution beam (beam 9) line-of-sight drift velocity of state 2 flow, especially during interval IV, is modulated by poleward-moving flow bursts which have a lifetime and recurrence period of approximately 2 minutes (see Fig. 6 and Sect. 3.2.2). Co-located with these velocity transients, and moving in tandem with them, are enhancements of the optical emission intensity. Such optical transients are observed during both intervals IV and VI, and are located within the continuous low latitude optical arc, interpreted as closed field lines. The velocity enhancements are observed within radar aurora associated with, and poleward of, the continuous optical arc, i.e. the velocity transients extend to higher latitudes than the optical transients, perhaps into the open field line region of the polar cap. These transient events do not appear directly related to the FTE signatures discussed above, though they do bear some similarity with the cusp observations of Pinnock et al. (1995), i.e. polewards-moving velocity enhancements. The 2 minute recurrence period is shorter than the timescales usually associated with FTEs. These transients appear highly periodic in nature, suggesting an association with magnetohydrodynamic wave phenomena. There is some evidence for wave activity in the $\mathrm{X}$ component magnetometer observations throughout intervals III to VI, especially at the lower latitude stations SOR, MAS, and MUO, located far equatorward of the cusp region. However, these waves have a period of approximately 7 minutes, significantly longer than that of the transients, indeed commensurate with that expected for high latitude field line resonances. Pulsations with these longer periods have previously been observed on closed field lines, equatorward of eastwards propagating patches of backscatter associated with FTEs (Walker et al., 1986).

\section{Summary}

Meridian-scanning photometer, coherent HF radar, and magnetometer observations of the noon and post-noon dayside auroral zone have been combined for an interval of predominantly IMF $B_{\mathrm{y}}, B_{\mathrm{z}}<0 \mathrm{nT}$ conditions. In the cusp region proper, the red line optical observations are consistent with a "midday gap" configuration, with occasional faint poleward-moving auroral forms, associated with weak and sporadic radar backscatter. In the post-noon sector, a much more intense continuous or persistent auroral arc is present, interpreted as LLBL/ BPS precipitation, the upward region 1 current system, on closed field lines. Poleward of this, periodic enhancements of the optical intensity are interpreted as the eastward passage of regions of mantle precipitation on field lines newly-opened in the cusp region, to the west of the MSP meridian. These periodic enhancements have a recurrence period of just over 8 minutes, consistent with the reported mean recurrence period of magnetopause flux transfer events. In general, the lower latitude boundary of the continuous arc steps equatorward and then recovers poleward with each passage of an FTE footprint. This is interpreted as a proxy for the motion of the open/closed field line boundary at higher latitudes, caused by the perturbation of the closed field lines at lower latitudes. The study reveals excellent colocation of the radar and optical aurora, especially at their equatorward boundary. The radar plasma drift measurements indicate that a convection reversal boundary exists between westward (sunward) flow at lower latitudes and eastward (antisunward) flow at higher latitudes, apparently near the peak in intensity of the region 1 current optical arc, i.e. on closed field lines. The optical enhancements associated with FTEs occur within the region of antisunward plasma drift.

The post-noon optical and radar aurora appear to exist in two states. In the first, the optical intensity of the region 1 current arc is high and azimuthal shear flow associated with the convection reversal boundary dominates the plasma drift pattern. In the second, this optical intensity is lower, and the plasma drift is modulated by polewards-propagating velocity enhancements. Co-located with these velocity bursts are enhancements of the region 1 current arc optical intensity. These modulations of drift velocity and optical intensity appear highly periodic, reminiscent of magnetohydrodynamic ULF wave activity, with a recurrence period of approximately 2 minutes. State 1 and state 2 auroral behaviour interchange on timescales of $10 \mathrm{~s}$ of minutes, with no obvious precursor in the IMF observations.

The present study has emphasised the power of the HF radar technique for cusp region studies, especially when combined with optical observations. It is clear, however, that greater spatial coverage and a higher time resolution is essential for future investigations of cusp dynamics.

Acknowledgements. CUTLASS is supported by the Particle Physics and Astronomy Research Council (PPARC), UK, the Swedish Institute for Space Physics, Uppsala, and the Finnish Meteorological Institute, Helsinki. SEM is supported on PPARC grant no. GR/L00865. The IMAGE magnetometer data employed in this paper were collected as a German-Finnish-Norwegian-Polish project conducted by the Geophysical Research Division of the Finnish Meteorological Institute (FMI/GEO). The WIND MFI observations were provided by R P Lepping of the Laboratory for Extraterrestrial Physics, NASA/Goddard Space Flight Centre, MD, USA.

Topical Editor K. -H. Glassmeier thanks A. Rodger and K. Baker for their help in evaluating this paper.

\section{References}

Atkinson, G., Magnetospheric flows and substorms, in Magnetosphere-Ionosphere Interactions, ed. K Folkestadt, 203, Universitetsforlaget, Oslo, Norway, 1972. 
Baker, K. B., A. S. Rodger, and G. Lu, HF-radar observations of the dayside magnetic merging rate: A Geospace Environment Modeling boundary layer campaign study, J. Geophys. Res., 102, 9603-9617, 1997.

Berchem, J., and C. T. Russell, Flux transfer events on the magnetopause: Spatial distribution and controlling factors, J. Geophys. Res., 89, 6689, 1984.

Cowley, S. W. H., The impact of recent observations on theoretical understanding of solar wind-magnetosphere interactions, J. Geomagn. Geoelectr., 38, 1223, 1986.

Cowley, S. W. H., J. P. Morelli, and M. Lockwood, Dependence of convective flows and particle precipitation in the high-latitude dayside ionosphere on the $X$ and $Y$ components of the interplanetary magnetic field, J. Geophys. Res., 96, 5557-5564, 1991.

Cowley, S. W. H., and M. Lockwood, Excitation and decay of solar wind-driven flows in the magnetosphere-ionosphere system, Ann. Geophys., 10, 103, 1992.

Cowley, S. W. H., J. P. Morelli, M. P. Freeman, M. Lockwood, and M. F. Smith, Excitation and decay of flows in the magnetosphere-ionosphere system due to magnetic reconnection at the dayside magnetopause and in the geomagnetic tail, Proceedings of the First International Conference on Substorms (ICS-1), Kiruna, Sweden, March 1992 (ESA SP-335), 117-123, 1992.

Elphic, R. C., M. Lockwood, S. W. H. Cowley, and P. E. Sandholt, Signatures of flux transfer events at the dayside magnetopause and in the ionosphere: Combined ISEE, EISCAT, and optical observations, Geophys. Res. Lett., 17, 2241-2244, 1990.

Elphinstone, R. D., J. S. Murphree, D. J. Hearn, L. L. Cogger, P. T. Newell, and H. Vo, Viking observations of the UV dayside aurora and their relation to DMSP particle boundary definitions, Ann. Geophys., 10, 815, 1992.

Fasel, G. J., J. I. Minow, R. W. Smith, C. S. Deehr, and L. C. Lee, Multiple brightenings of transient dayside auroral forms during oval expansions, Geophys. Res. Lett., 19, 2429, 1992.

Fasel, G. J., Dayside poleward moving auroral forms: A statistical study, J. Geophys. Res., 100, 11891, 1995.

Feldstein, Y. I., and G. V. Starkov, Dynamics of auroral belt and polar geomagnetic disturbances, Planet. Space Sci., 15, 209230, 1967.

Friis-Christensen, E., M. A. McHenry, C. R. Clauer, and S. Vennerstrom, Ionospheric travelling convection vortices observed near the polar cleft: a triggered response to sudden changes in the solar wind, Geophys. Res. Lett., 15, 253, 1988.

Goertz, C. K., E. Neilsen, A. Korth, K.-H. Glassmeier, C. Haldoupis, P. Hoeg, and D. Hayward, Observations of a possible signature of flux transfer events, J. Geophys. Res., 90, 4069, 1985.

Greenwald, R. A., K. B. Baker, J. R. Dudeney, M. Pinnock, T. B. Jones, E. C. Thomas, J.-P. Villain, J.-C. Cerisier, C. Senior, C. Hanuise, R. D. Hunsucker, G. Sofko, J. Koehler, E. Nielsen, R. Pellinen, A. D. M. Walker, N. Sato, and H. Yamagishi, DARN/ SuperDARN: A global view of the dynamics of high-latitude convection, Space Sci. Rev., 71, 761-796, 1995.

Haerendel, G., G. Paschmann, N. Sckopke, H. Rosenbauer, and P. C. Hedgecock, The frontside boundary layer of the magnetopause and the problem of reconnection, J. Geophys. Res., 83, 3195, 1978.

Holzworth, R. H., and C.-I. Meng, Mathematical representation of the auroral oval, Geophys. Res. Lett., 2, 377-380, 1975.

Horwitz, J. L., and S.-I. Akasofu, The response of the dayside aurora to sharp northward and southward transitions of the interplanetary magnetic field and to magnetospheric substorms, J. Geophys. Res., 82, 2723, 1977.

Jørgensen, T. S., E. Friis-Christensen, and J. Wilhjelm, Interplanetary magnetic field direction and high latitude ionospheric currents, J. Geophys. Res., 77, 1976, 1972.

Karlson, K. A., M. Oieroset, J. Moen, and P. E. Sandholt, A statistical study of flux transfer event signatures in the dayside aurora: The IMF $B_{\mathrm{y}}$-related prenoon-postnoon asymmetry, J. Geophys. Res., 101, 59-68, 1996.
Lee, L. C., Magnetic flux transfer at the Earth's magnetopause, in Solar Wind-Magnetosphere Coupling, eds. Y Kamide and J A Slavin, Terra Sci., Tokyo, 1986.

Lockwood, M., P. E. Sandholt, and S. W. H. Cowley, Dayside auroral activity and magnetic flux transfer from the solar wind, Geophys. Res. Lett., 16, 33, 1989a.

Lockwood, M., P. E. Sandholt, S. W. H. Cowley, and T. Oguti, Interplanetary magnetic field control of dayside auroral activity and the transfer of momentum across the dayside magnetopause, Planet. Space Sci., 37, 1347, 1989b.

Lockwood, M., S. W. H. Cowley, P. E. Sandholt, and R. D. Lepping, The ionospheric signatures of flux transfer events and solar wind dynamic pressure changes, J. Geophys. Res., 95, $17113,1990$.

Lockwood, M., The excitation of ionospheric convection, J. Atmos. Terr. Phys., 53, 177-199, 1991

Lockwood, M., and S. W. H. Cowley, Ionospheric convection and the substorm cycle, Proceedings of the First International Conference on Substorms (ICS-1), Kiruna, Sweden, March 1992 (ESA SP-335), 99-110, 1992.

Lockwood, M., and M. N. Wild, On the quasi-periodic nature of magnetopause flux transfer events, J. Geophys. Res., 98, 59355940, 1993.

Lockwood, M., H. C. Carlson, and P. E. Sandholt, The implications of the altitude of transient $630 \mathrm{~nm}$ dayside auroral emissions, J. Geophys. Res., 98, 15571, 1993a.

Lockwood, M., W. F. Denig, A. D. Farmer, V. N. Davda, S. W. H. Cowley, and H. Lühr, Ionospheric signatures of pulsed magnetic reconnection at the Earth's magnetopause, Nature, 361 (6411), 424, 1993b.

Lockwood, M., J. Moen, S. W. H. Cowley, A. D. Farmer, U. P. Løvhaug, H. Lühr, and V. N. Davda, Variability of dayside convection and motions of the cusp/cleft aurora, Geophys. Res. Lett., 20, 1011, 1993c.

Lockwood, M., and C. J. Davis, On the longitudinal extent of magnetopause reconnection pulses, Ann. Geophys., 14, 865-878, 1996.

Milan, S. E., T. B. Jones, T. R. Robinson, E. C. Thomas, and T. K. Yeoman, Interferometer evidence for the observation of ground backscatter from behind the CUTLASS radars, Ann. Geophys, 15, 29-39, 1997.

Moen, J., P. E. Sandholt, M. Lockwood, W. F. Denig, U. P. Løvhaug, B. Lybekk, A. Egeland, D. Opsvik, and E. FriisChristensen, Events of enhanced convection and related dayside auroral activity, J. Geophys. Res., 100, 23917-23934, 1995.

Moen, J., M. Lockwood, P. E. Sandholt, U. P. Løvhaug, W. F. Denig, A. P. van Eyken, and A. Egeland, Variability of dayside high-latitude convection associated with a sequence of auroral transients, J. Atmos. Terr. Phys., 58, 85-96, 1996.

Murphree, J. S., L. L. Cogger, C. D. Anger, S. Ismail, and G. G. Shepherd, Large scale $6300 \AA, 5577 \AA, 3914 \AA$ dayside auroral morphology, Geophys. Res. Lett., 7, 239, 1980.

Newell, P. T., and C.-I. Meng, The cusp and the cleft/LLBL: Lowaltitude identification and statistical local time variation, J. Geophys. Res., 93, 14549, 1988.

Øieroset, M., H. Lühr, J. Moen, T. Moretto, and P. E. Sandholt, Dynamical auroral morphology in relation to ionospheric plasma convection and geomagnetic activity: Signatures of magnetopause $\mathrm{X}$ line dynamics and flux transfer events, J. Geophys. Res., 101, 13275-13292, 1996.

Paschmann, G., G. Haerendel, I. Papmastorakis, N. Sckopke, S. J. Bame, J. T. Gosling, and C. T. Russell, Plasma and magnetic field characteristics of magnetic flux transfer events, J. Geophys. Res., 87, 2159, 1982.

Pinnock, M., A. S. Rodger, J. R. Dudeney, K. B. Baker, P. T. Newell, R. A. Greenwald, and M. E. Greenspan, Observations of an enhanced convection channel in the cusp ionosphere, J. Geophys. Res., 98, 3767-3776, 1993.

Pinnock, M., A. S. Rodger, J. R. Dudeney, F. Rich, and K. B. Baker, High spatial and temporal resolution observations of the ionospheric cusps, Ann. Geophys., 13, 919-925, 1995. 
Potemra, T. A., Sources of large-scale Birkelend currents, in Physical Signatures of Magnetospheric Boundary Layer Processes, 3-27, Kluwer Academic Publishers, The Netherlands, 1994.

Provan, G., T. K. Yeoman, and S. E. Milan, CUTLASS Finland radar observations of the ionospheric signatures of flux transfer events and the resulting plasma flows, Ann. Geophys., in press, 1998.

Rijnbeek, R. P., S. W. H. Cowley, D. J. Southwood, and C. T. Russell, A survey of dayside flux transfer events observed by the ISEE-1 and -2 magnetometers, J. Geophys. Res., 89, 786, 1984.

Rodger, A. S., S. B. Mende, T. J. Rosenberg, and K. B. Baker, Simultaneous optical and HF radar observations of the ionospheric cusp, Geophys. Res. Lett., 22, 2045, 1995.

Rodger, A. S., and M. Pinnock, The ionospheric response to flux transfer events: the first few minutes, Ann. Geophys., 15, 685691, 1997.

Russell, C. T., and R. C. Elphic, Initial ISEE magnetometer results: Magnetopause observations, Space Sci. Rev., 22, 681, 1978.

Sandholt, P. E., A. Egeland, J. A. Holtet, B. Lybekk, K. Svenes, and S. Asheim, Large- and small-scale dynamics of the polar cusp, J. Geophys. Res., 90, 4407, 1985.

Sandholt, P. E., S. Deehr, A. Egeland, B. Lybekk, R. Viereck, and G. J. Romick, Signatures in the dayside aurora of plasma transfer from the magnetosheath, J. Geophys. Res., 91, 1006310079, 1986.

Sandholt, P. E., IMF control of the cusp and cleft auroras, $A d v$. Space Res., 8, 21, 1988.

Sandholt, P. E., B. Lybekk, A. Egeland, B. Jacobson, P. F. Bythrow, and D. A. Hardy, Electrodynamics of the polar cusp ionosphere: A case study, J. Geophys. Res., 94, 6713, 1989.

Sandholt, P. E., M. Lockwood, T. Oguti, S. W. H. Cowley, K. S. C. Freeman, B. Lybekk, A. Egeland, and D. M. Willis, Midday auroal breakup events and related energy and momentum transfer from the the magnetosheath, J. Geophys. Res., 95, 1039, 1990.

Sandholt, P. E., J. Moen, D. Opsvik, W. F. Denig, and W. J. Burke, Auroral event sequence at the dayside polar cap boundary: Signature of time-varying solar wind-magnetosphere-ionosphere coupling, Adv. Space Res., 13, (4)7-(4)15, 1993.

Sandholt, P. E., C. J. Farrugia, P. Stauning, S. W. H. Cowley, and T. Hansen, Cusp/cleft auroral forms and activities in relation to

Note added in proof Please note that the zenith angles indicated in Fig. 1 are in the reverse sense to the zenith angle scale of Fig. 3. ionospheric convection: Responses to specific changes in solar wind and interplanetary magnetic field conditions, J. Geophys. Res., 101, 5003-5020, 1996.

Sandholt, P. E., C. J. Farrugia, J. Moen, N. Øystein, B. Lybekk, T. Sten, and H. Truls, A classification of dayside auroral forms and activities as a function of IMF orientation, J. Geophys. Res., in press, 1998.

Saunders, M. A., C. T. Russell, and N. Sckopke, Flux transfer events: Scale size and interior structure, Geophys. Res. Lett., 11, 131, 1984.

Saunders, M. A., Origin of the cusp Birkland currents, Geophys. Res. Lett., 16, 151, 1989.

Scholer, M., Magnetic flux transfer at the magnetopause based on single X-line bursty reconnection, Geophys. Res. Lett., 15, 291, 1988.

Siscoe, G. L., and T. S. Huang, Polar cap inflation and deflation, J. Geophys. Res., 90, 543, 1985.

Smith, M. F., and M. Lockwood, Earth's magnetospheric cusps, Rev. Geophys., 34, 233-260, 1996.

Southwood, D. J., Theoretical aspects of ionosphere-magnetosphere-solar wind coupling, Adv. Space Res., 5, 7, 1985.

Southwood, D. J., The ionospheric signature of flux transfer events, J. Geophys. Res., 92, 3207, 1987.

Southwood, D. J., C. J. Farrugia, and M. A. Saunders, What are flux transfer events?, Planet. Space Sci., 36, 503-508, 1988.

van Eyken, A. P., H. Rishbeth, D. M. Willis, and S. W. H. Cowley, Initial observations of plasma convection at invarient latitudes 70-77, J. Atmos. Terr. Phys., 46, 635, 1984.

Vorobjev, V. G., G. Gustafsson, G. V. Starkov, Y. I. Feldstein, and N. F. Shevnina, Dynamics of day and night aurora during substorms, Planet. Space Sci., 23, 269, 1975.

Walker, A. D. M., R. A. Greenwald, and K. B. Baker, HF radar observations of pulsations near the magnetospheric cusp, J. Geophys. Res., 91, 8919-8928, 1986.

Wei, C. Q., and L. C. Lee, Ground magnetic signatures of moving elongated plasma clouds, J. Geophys. Res., 95, 2405, 1990.

Whalen, J. A., J. Buchau, and R. A. Wagner, Airbourne ionospheric and optical observations of noontime aurora, J. Atmos. Terr. Phys., 33, 661, 1971. 